\title{
Zoonotic Abbreviata caucasica in Wild Chimpanzees (Pan troglodytes verus) from Senegal
}

\author{
Younes Laidoudi 1,2®, Hacène Medkour ${ }^{1,2} \oplus$, Maria Stefania Latrofa ${ }^{3}$, Bernard Davoust ${ }^{1,2}$, \\ Georges Diatta 2,4,5, Cheikh Sokhna 2,4,5, Amanda Barciela ${ }^{6}{ }^{\circ}$, R. Adriana Hernandez-Aguilar 6,7 (D), \\ Didier Raoult $^{1,2}$, Domenico Otranto ${ }^{3}(\mathbb{D})$ and Oleg Mediannikov $1,2, * \mathbb{D}$ \\ 1 IRD, AP-HM, Microbes, Evolution, Phylogeny and Infection (MEPHI), IHU Méditerranée Infection, \\ Aix Marseille Univ, 19-21, Bd Jean Moulin, 13005 Marseille, France; younes.laidoudi@yahoo.com (Y.L.); \\ hacenevet1990@yahoo.fr (H.M.); bernard.davoust@gmail.com (B.D.); didier.raoult@gmail.com (D.R.) \\ 2 IHU Méditerranée Infection, 19-21, Bd Jean Moulin, 13005 Marseille, France; georges.diatta@ird.fr (G.D.); \\ cheikh.sokhna@ird.fr (C.S.) \\ 3 Department of Veterinary Medicine, University of Bari, 70010 Valenzano, Italy; \\ maria.latrofa@uniba.it (M.S.L.); domenico.otranto@uniba.it (D.O.) \\ 4 IRD, SSA, APHM, VITROME, IHU Méditerranée Infection, Aix-Marseille University, 19-21, Bd Jean Moulin, \\ 13005 Marseille, France \\ 5 VITROME, IRD 257, Campus International UCAD-IRD, Hann, Dakar, Senegal \\ 6 Jane Goodall Institute Spain and Senegal, Dindefelo Biological Station, Dindefelo, Kedougou, Senegal; \\ amanda.b@janegoodall.es (A.B.); r.a.hernandez-aguilar@ibv.uio.no (R.A.H.-A.) \\ 7 Department of Social Psychology and Quantitative Psychology, Faculty of Psychology, University of \\ Barcelona, Passeig de la Vall d'Hebron 171, 08035 Barcelona, Spain \\ * Correspondence: olegusss1@gmail.com; Tel.: +33-041-373-2401
}

Received: 19 April 2020; Accepted: 23 June 2020; Published: 27 June 2020

\begin{abstract}
Abbreviata caucasica (syn. Physaloptera mordens) has been reported in human and various non-human primates including great apes. The identification of this nematode is seldom performed and relies on egg characterization at the coproscopy, in the absence of any molecular tool. Following the recovery of two adult females of A. caucasica from the feces of wild Senegalese chimpanzees, morphometric characteristics were reported and new data on the width of the esophagus $(0.268-0.287 \mathrm{~mm})$ and on the cuticle structure $(0.70-0.122 \mathrm{~mm})$ were provided. The molecular characterization of a set of mitochondrial (cox1, 16S rRNA, 12S rRNA) and nuclear (18S rRNA and ITS2) partial genes was performed. Our phylogenetic analysis indicates for the first time that A. caucasica is monophyletic with Physaloptera species. A novel molecular tool was developed for the routine diagnosis of A. caucasica and the surveillance of Nematoda infestations. An A. caucasica-specific qPCR targeting the $12 \mathrm{~S}$ gene was assessed. The assay was able to detect up to $1.13 \times 10^{-3} \mathrm{eggs} / \mathrm{g}$ of fecal matter irrespective of its consistency, with an efficiency of $101.8 \%$ and a perfect adjustment $\left(R^{2}=0.99\right)$. The infection rate by A. caucasica in the chimpanzee fecal samples was $52.08 \%$. Only $6.19 \%$ of the environmental samples were positive for nematode DNA and any for A. caucasica. Our findings indicate the need for further studies to clarify the epidemiology, circulation, life cycle, and possible pathological effects of this infestation using the molecular tool herein developed.
\end{abstract}

Keywords: Abbreviata caucasica; Physaloptera mordens; Pan troglodytes verus; wild chimpanzees; nematode; zoonosis; Senegal

\section{Introduction}

Physalopteriasis is caused by parasitic nematodes from the genus Physaloptera (Spirurida, Physalopteridae) [1], which has been distributed in Africa and the Middle East (i.e., Iran) since 
prehistoric times [2,3]. Following the first formal description of the Physaloptera genus (Rudolphi in 1819), Physaloptera abbreviata (Rudolphi, 1819) was designated as the type species [4]. Afterward, Abbreviata was defined as a distinct genus, based on the number, mode, and origin of the uteri, which constitute the main keys for genus differentiation [4]. Adult stages of this genus are found in the stomach of a variety of animals such as reptiles and mammals including humans [5].

Abbreviata (=Physaloptera) caucasica (Linstow 1902), is a gastrointestinal nematode of Simiiformes (Anthropoidea) members [6]. After its discovery in a Caucasian man, Linstow (1902) provided an incomplete description with some erroneous morphological details [7]. In 1926, Schulz gave the complete description of $A$. caucasica after re-examining the original specimens, establishing a close relationship of this species with Physaloptera mordens (Leiper, 1908) isolated from humans in Central Africa. The unique difference identified among specimens was the presence/absence of a series of small teeth between and exterior to the large teeth on the inner face of the lip of A. caucasica and P. mordens, respectively [8]. A few months later, Ortlepp re-examined P. mordens and confirmed that the small teeth were missing in the previous examinations [9], therefore synonymizing P. mordens (Leiper, 1908) and A. caucasica (Linstow, 1902).

The A. caucasica infection has been reported in New and Old World monkeys [10], rhesus macaques (Macaca mulatta), baboons (Papio spp.), and great apes including both captive (Pongo spp.) and wild (Pongo abelii) [1,11]. It has also been reported in chimpanzees (Pan troglodytes) from Gombe (Tanzania) and Ngogo (Uganda) [12,13], although no adult specimens were examined. Furthermore, eggs of Physaloptera sp. have been reported in wild Senegalese chimpanzees [12,14]. Human and non-human primates probably constitute the natural host for A. caucasica [8]. The adult parasite looks like Ascaris sp. under the naked eye [15] and occurs in the digestive tract from the esophagus to the small intestine, where it can induce serious disease manifestations such as abdominal pain, anorexia, vomiting, and bloody diarrhea [2]. Records of the clinical signs in infected chimpanzees are lacking [6]. Nowadays, the detection of $A$. caucasica depends on the identification of eggs in the feces or in the detection of adult stages during post-mortem examination of the gastrointestinal tract of infested hosts [1]. The arthropod intermediate and/or paratenic hosts remain unknown though some experimental evidence indicates that A. caucasica could develop to the infective stage in Blatella germanica and in Schistocerca gregaria [5]. For other Physaloptera species, the intermediate arthropod host has been assessed such as Tribolium confusum [16], ground beetles, Harpalus sp. [17] as well as crickets, Acheta assimilis, and grasshoppers, Melanoplus femurrubrum [18,19].

Under natural conditions, A. caucasica may develop in arthropods and infestation probably occurs through ingestion of beetles, crickets, or other arthropods as well as paratenic hosts containing infective larvae $[8,15]$. However, the potential involvement of up to 28 paratenic and second intermediate hosts is suspected [6]. Anthelminthic drugs have been reported to be effective for the treatment of physalopteriasis in non-human primates [1]. However, their control should be reinforced by a molecular characterization to avoid the misleading conclusions about this parasite, sanitation and control of the potential paratenic or arthropod hosts as well as the surveillance of the infestation from the colon of non-human primates [1,16].

As part of the control of infectious and zoonotic diseases in the current chimpanzee population from the Dindefelo Community Natural Reserve in Senegal, we present here morphometric and phylogenetic findings to support the occurrence of A. caucasica in chimpanzees, providing a molecular characterization of a set of target mitochondrial (cox1, 16S rRNA, 12S rRNA) and nuclear (18S rRNA and ITS2) genes and morphological identification of adult specimens collected from feces of West African chimpanzees in Senegal. In addition, we developed a molecular test that could be used in a routine diagnostic laboratory instead of the labor-intensive coprological methods. The molecular test provides detection, egg quantification, and genetic characterization of $A$. caucasica from biological samples. We therefore applied this tool to a surveillance process and molecular xenomonitoring of A. caucasica from possible intermediate hosts and our current population of West African chimpanzees from Senegal. 


\section{Results}

\subsection{Morphological Characteristics of Adult A. caucasica}

Comparative measurements of A. caucasica adult females from our study with A. caucasica (Linstow, 1902) and its synonymous species $P$. mordens (Lipper, 1908) [8] are detailed in Table 1 . Two female complete specimens measuring $54.7 \mathrm{~mm}$ and $59.6 \mathrm{~mm}$ in length and $2.08 \mathrm{~mm}$ and $2.13 \mathrm{~mm}$ in width, respectively, were examined. The nematodes were characterized by the anterior end with a short buccal cavity (Figure 1(1a)) and by a cuticle reflecting over the lips to form a cephalic collarette (Figure 1(1b)) with two lateral pseudolabia undivided (Figure $1(1 \mathrm{c}, 1 \mathrm{~d})$ ). Nerve ring at $0.430 \mathrm{~mm}$ from the anterior end.

The esophagus consisting of two parts: muscular esophagus $0.75 \mathrm{~mm}$ long (Figure 1(2a)) and $0.287 \mathrm{~mm}$ wide, $0.79 \mathrm{~mm}$ long, and $0.268 \mathrm{~mm}$ wide, respectively. The esophagus total length was 5.52 $\mathrm{mm}$ and $4.82 \mathrm{~mm}$, respectively in two samples.

In the mid-body, the cuticle was $0.70-0.122 \mathrm{~mm}$ thick and finely striated (Figure $1(2 \mathrm{~b})$ ). The worms showed the presence of two small symmetrical pins in the front third of the body (Figure 1(2c)). Vulva $1.560 \mathrm{~mm}$ from anterior end (Figure 1(2d)). Presence of four uteri (Figure 1(3a)). Eggs were small 36-41 $\mu \mathrm{m} \times 28-32 \mu \mathrm{m}$ (Figure 1(3b)). Tail length was $1.084 \mathrm{~mm}$ (Figure 1(3c)). The caudal end showed the presence of a caudal appendix (Figure 1(3d)). 
Table 1. Comparative measurement (in mm unless specified) of adult female of A. caucasica from our study with A. caucasica (Linstow, 1902) and its synonymous species P. mordens (Lipper, 1908) according to Fain and Vandepitte (1964) [7], Linstow (1902) and Schulz (1926) [8].

\begin{tabular}{|c|c|c|c|c|c|c|c|c|c|c|}
\hline \multirow{3}{*}{\multicolumn{2}{|c|}{ Measures }} & \multirow{2}{*}{\multicolumn{2}{|c|}{$\begin{array}{l}\text { This Study } \\
\text { A. caucasica }\end{array}$}} & \multirow{2}{*}{\multicolumn{2}{|c|}{$\begin{array}{c}\text { Measurement of Fain and } \\
\text { Vandepitte (1964) } \\
\begin{array}{c}\text { A. caucasica (Syn. P. } \\
\text { mordens) }\end{array} \\
\end{array}$}} & \multirow{4}{*}{$\begin{array}{c}\begin{array}{c}\text { Measurement of } \\
\text { Linstow, } 1902\end{array} \\
\begin{array}{c}\text { A. caucasica: } \\
\text { Type Species }\end{array} \\
\text { Men (caucasia) } \\
\text { Adult Female }\end{array}$} & \multicolumn{4}{|c|}{ Measurement of Schulz (1926) } \\
\hline & & & & & & & \multirow{2}{*}{\multicolumn{2}{|c|}{$\begin{array}{c}\text { A. caucasica: Type Species } \\
\text { Men (caucasia) }\end{array}$}} & \multirow{2}{*}{\multicolumn{2}{|c|}{$\begin{array}{c}\text { P. Mordens: Type Species } \\
\text { Men (Uganda) }\end{array}$}} \\
\hline & & \multicolumn{2}{|c|}{ Chimpanzee (Senegal) } & \multicolumn{2}{|c|}{ Men (Congo) } & & & & & \\
\hline Organ & Segment & CHS 11 & CHS 31 & N1 & N1 & & N1 & N2 & N1 & N2 \\
\hline \multirow{3}{*}{ Body } & Length & 54.7 & 59.6 & 108 & 117 & 27 & 24.75 & 23.84 & 41 & 100 \\
\hline & Width & 2.08 & 2.13 & 2 & 3 & 1.14 & 1.18 & 1.12 & 1.8 & 2.8 \\
\hline & Index a & 26.3 & 28 & 54 & 39 & 23.68 & 20.97 & 21.29 & 22.78 & 35.71 \\
\hline Nerve ring & $\begin{array}{c}\text { From the } \\
\text { anterior end }\end{array}$ & 0.43 & - & 0.7 & 0.78 & - & 0.454 & 0.454 & - & - \\
\hline \multirow{4}{*}{$\begin{array}{l}\text { Esophagus } \\
\text { (e) }\end{array}$} & Total length & 5.52 & 4.82 & 9 & 11 & - & 3.5 & 3.72 & - & - \\
\hline & $\begin{array}{l}\text { Length } \\
\text { muscolar (e) }\end{array}$ & 0.79 & 0.75 & 0.6 & 0.6 & - & 0.43 & 0.35 & - & - \\
\hline & Width & 0.268 & 0.287 & & & - & - & - & - & - \\
\hline & Index b & 9.91 & 12.37 & 12 & 10.63 & - & 7 & 6.4 & 6.2 & 6.2 \\
\hline Cuticle & Width & $0.92-0.102$ & $0.70-0.122$ & - & - & - & - & - & - & - \\
\hline Vulva & $\begin{array}{l}\text { From the } \\
\text { anterior end }\end{array}$ & 1.56 & - & 21 & 23 & - & 3.50 & 4.62 & - & - \\
\hline Eggs $(\mu \mathrm{m})$ & & $37-41 \times 28-32$ & $36-39 \times 28-31$ & \multicolumn{2}{|c|}{$60-65 \times 45-55$} & $57 \times 39$ & \multicolumn{2}{|c|}{$57-62 \times 42-45$} & \multicolumn{2}{|c|}{$45-49 \times 32-34$} \\
\hline \multirow{2}{*}{ Tail } & Tail & 1.084 & - & 1.3 & 1.4 & 0.51 & 0.578 & 0.532 & - & - \\
\hline & Index c & 50.46 & - & 80 & 83 & 53 & 43 & 45 & 70 & 90 \\
\hline
\end{tabular}

CHS 11 and CHS31: Code sample of specimens from the present study. N1, N2: Code samples of specimens from the study of Schulz (1926). Index a, b, and c are the ratio of body length to

body width, esophagus length and tail length, respectively. 


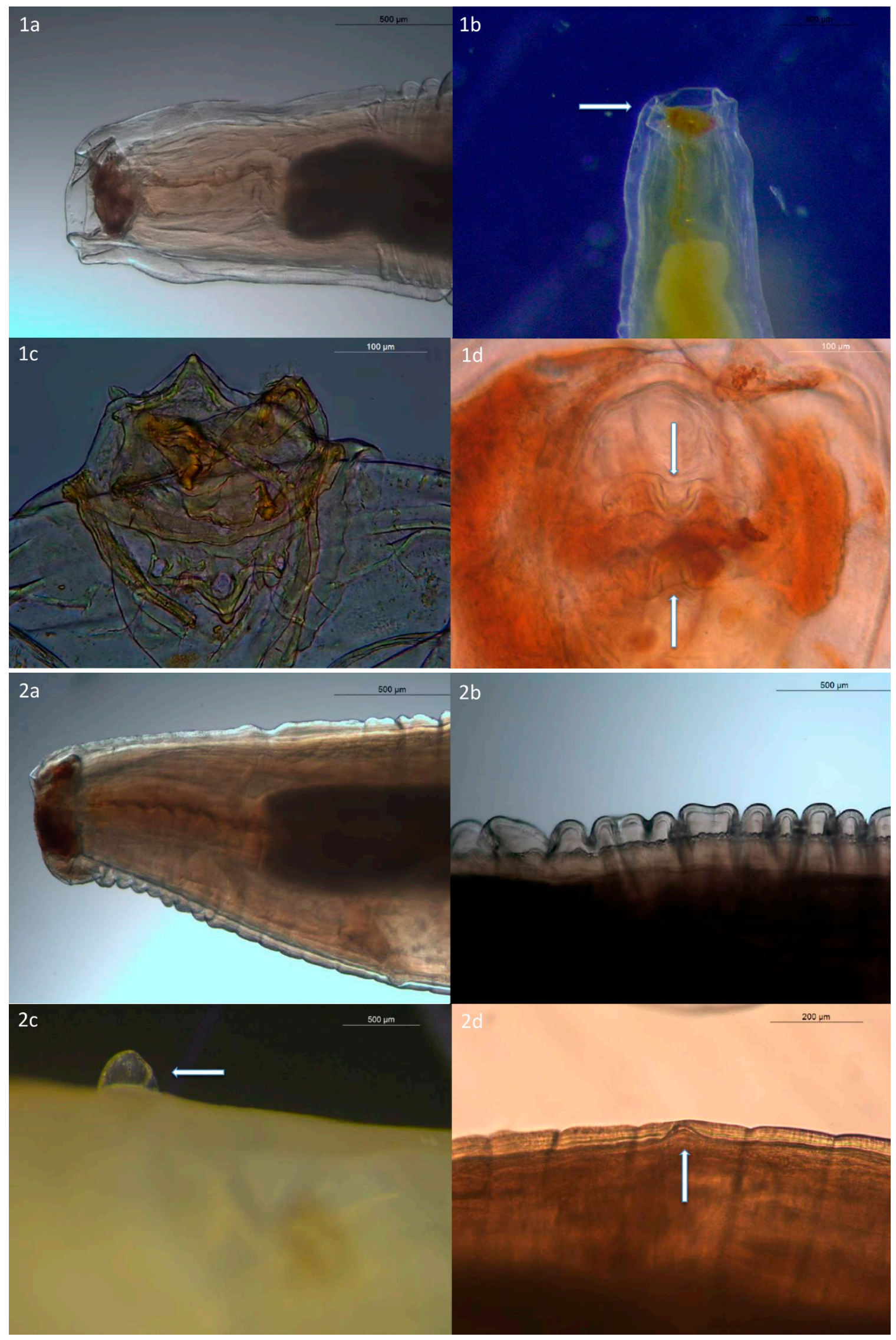

Figure 1. Cont. 


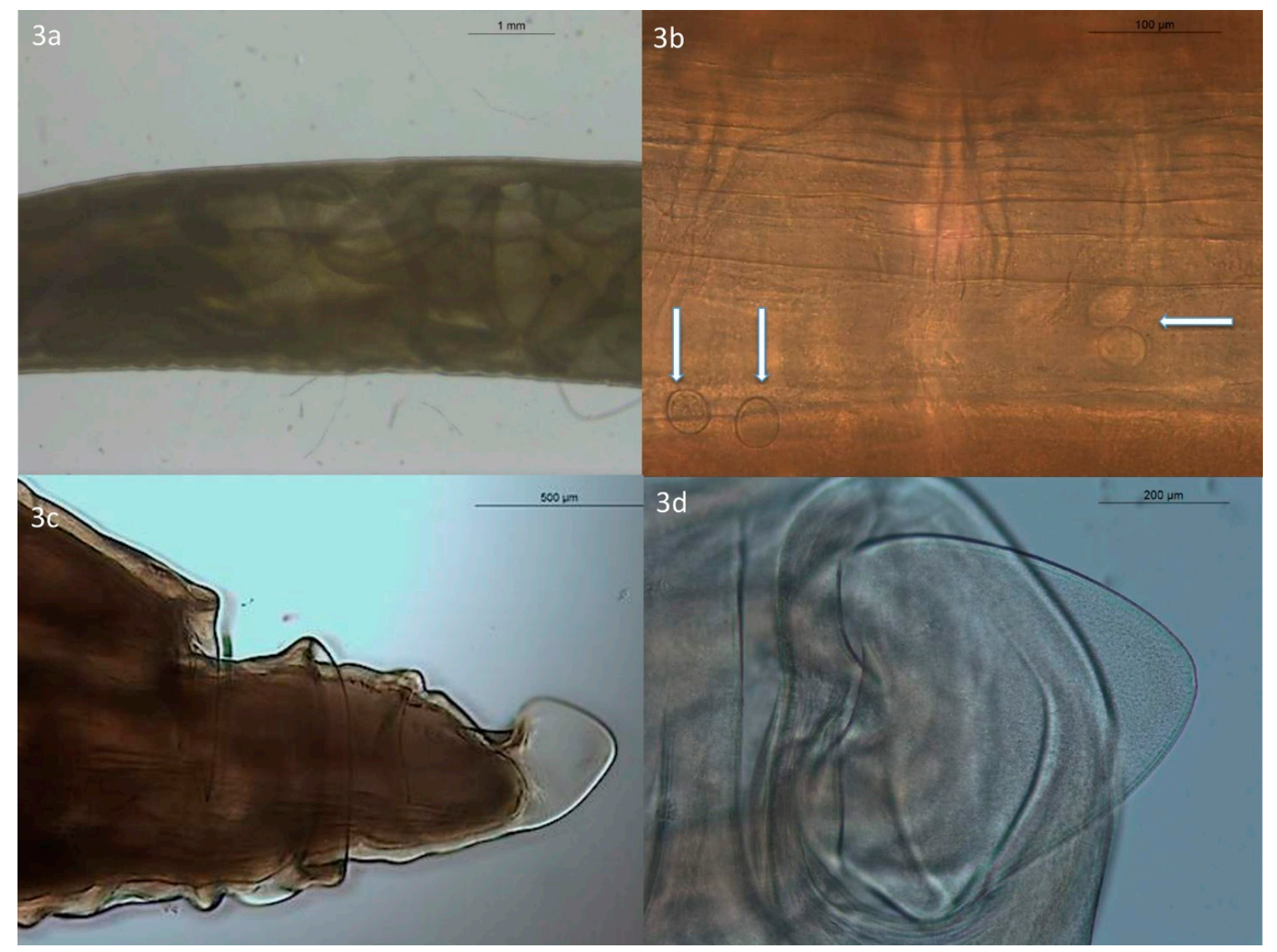

Figure 1. Light microscopy images of A. caucasica adult females. (1a) Buccal cavity. (1b) Cephalic collarette. (1c, 1d) The two lateral pseudolabia. (2a) Esophagus. (2b) Thick finely striated from the mid-body. (2c) Pins. (2d) Vulva. (3a) Uteri. (3b) Eggs. (3c) Tail. (3d) Caudal appendix.

\subsection{A. caucasica Eggs from Positive Feces}

Eggs of A. caucasica were identified morphologically from two fecal samples taken from animals found infested with adult worms. The eggs were apparently identical to the micrograph of $A$. caucasica eggs reported elsewhere [7]. Eggs were embryonated and had a characteristic thick shell and hyaline coat (Figure 2).

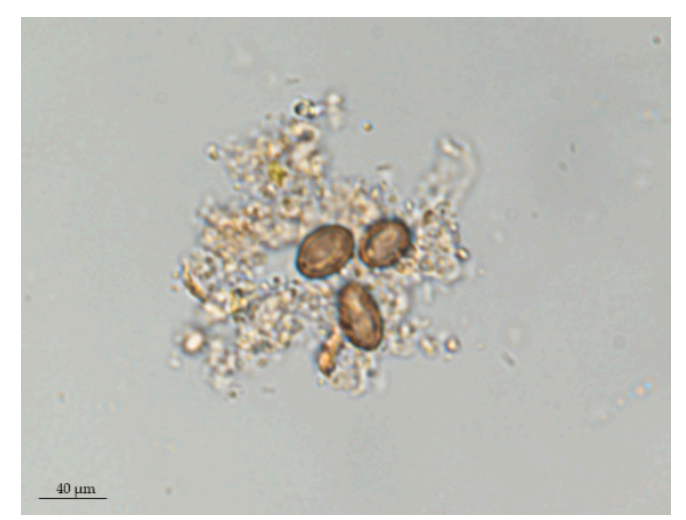

Figure 2. Coproscopy showing the A. caucasica eggs found in wild chimpanzee feces (formol-ether method, 100× magnification). 


\subsection{Molecular Characterization of Adult A. caucasica Worms}

First, nearly full-length DNA sequences of the 18S rRNA (AN: MN956824, MN956825), ITS2 (AN: MN956809, MN956810), cox1 (AN: MT231294, MT231295), 16S rRNA (AN: MN956826, MN956827), and 12S rRNA (AN: MN956811, MN956812) genes were obtained from adult worms of A. caucasica. The sequences of each gene were identical to each other. The BLAST analysis of $1140 \mathrm{bp}$ of the $18 \mathrm{~S}$ rRNA gene showed the highest query cover $(100 \%)$ with eight sequences of Physaloptera sp. A nucleotide identity of $97.9 \%$ (1118/1142) was observed with Physaloptera apivori (EU004817) isolated from birds in Germany, followed by $97.89 \%$ (1116/1140) for both Physaloptera sp. (HM067978) isolated from long-tailed macaques (Macaca fascicularis) in China, and Physaloptera turgida (DQ503459) isolated from North American opossums (Didelphis virginiana) in Louisiana, USA. Finally, an identity ranging from $97.46 \%$ to $97.81 \%$ was observed within the five other sequences of Physaloptera species isolated from reptiles and mammals (EF180069, MG808040, JF934734, AY702703, and EF180065).

In contrast, the BLAST analysis of the partial (759 bp) cox 1 nucleotide sequence showed the lowest values of query cover and identity with those of Physaloptera spp. from the GenBank database, having a greater sequence coverage (i.e., 98 to $100 \%$ ) with those of Onchocercidae members than that observed for Physaloptera species (i.e., 83 to $88 \%$ ). Among Physaloptera, the highest nucleotide identity values observed were 83.7\% (529/632) with Physaloptera sp. (MH752202) isolated from brown anoles (Anolis sagrei) in the USA, 83.5\% (530/635) with both P. turgida (KT894808) and Turgida sp. (KC130680) isolated from opossums (Didelphis spp.) in Brazil and Mexico, respectively, and 83.2\% (558/671) with P. amazonica (MK309356) isolated from Gardner's spiny rat (Proechimys gardneri) in Brazil, whilst lower identity values, ranging from $82.1 \%$ to $82.9 \%$, were observed for the other five sequences of Physaloptera species (MH782844, KT894803, KT894804, KP981418, KT894805).

In contrast, the Physaloptera cox 1 amino acid sequence appeared first among the top ten sequences of BLASTx [20]. Abbreviata caucasica COI sequence (protein id: QIP66136) showed an identity of 88.1\% with P. retusa (AMX28288) isolated from golden tegu (Tupinambis teguixin) in Brazil, $87.7 \%$ with P. mirandai (AMX28289) isolated from brown four-eye opossums (Metachirus nudicaudatus) in Brazil with a coverage of $86 \%$ for both, $87.5 \%$ of identity and $98 \%$ of coverage with P. rara (QDF64304) isolated from dogs (Canis lupus familiaris), and $87.2 \%$ of identity and $86 \%$ of coverage with Physaloptera sp. (AMX28292), P. bispiculata (AMX28291), P. amazonica (QDX15779), and P. hispida (QCF40948).

BLASTn analyses of $16 \mathrm{~S}$ rRNA ( $416 \mathrm{bp}$ ) and 12S rRNA (573 bp) sequences identified the first 60 sequences that corresponded to those of Filarioidea and Thelazidae without any Physaloptera. Nucleotide identity of about $75 \%$ with a query coverage of more than $99 \%$ were observed among these Spiriruds. Finally, the BLASTn analysis of the partial $(675 \mathrm{bp})$ sequence of the ITS2 showed an identity of $93.37 \%$ (67/71) and a coverage of $10 \%$ with the unique GenBank sequence of Physaloptera alata (AY702694) isolated from birds.

The interspecific nucleotide pairwise (INP) distance of the $18 \mathrm{~S}$ rRNA, cox1, 16S rRNA, $12 \mathrm{~S}$ rRNA, and ITS2 of A. caucasica within Physalopteridae members are shown in Table S1. All sequences were well resolved in the chromatograms. The partial cox 1 sequence was correctly aligned against the complete cox1 sequence (MH931178) of P. rara and no stop codon was observed in the translated amino-acid sequences, suggesting the absence of co-amplified numts. Furthermore, sequence alignment of COI with those of Physaloptera species showed nineteen amino-acid changes specific for A. caucasica (Figure S1). The interspecific nucleotide pairwise (INP) distance among the $645 \mathrm{bp}$ of cox 1 corroborated with the IaaP distance, among the corresponding 208 amino acid (Figure 3) and was substantially higher (ten times) between A. caucasica and Physalopteridae members in comparison with the $18 \mathrm{~S}$ rRNA sequences. 


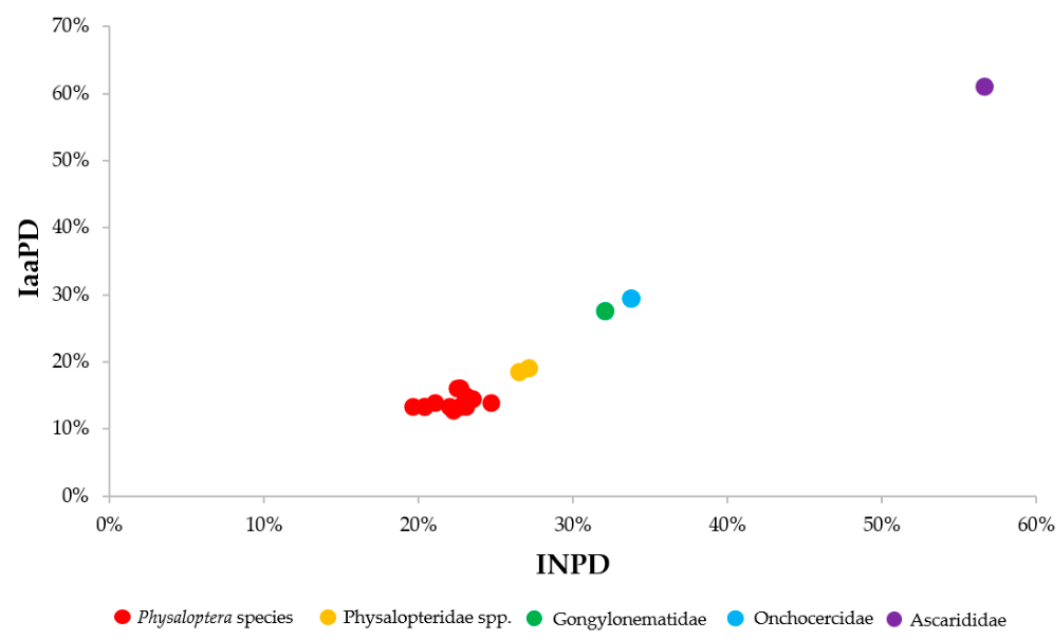

Figure 3. Scatter chart showing the interspecific pairwise distance between the COI sequence of A. caucasica and other nematodes based on both IaaPD and INPD. The INP distance was 0.31 (Std Err: 0.03) and 0.21 (Std Err: 0.06) between A. caucasica and Heliconema longissimum for THE 12S rRNA (GQ332423) and 16S rRNA (GQ332423) sequences, respectively. for the ITS2 sequences, the INP distance observed between A. caucasica and Filarioidea (XR 002251420, JQ316671, FM206482, DQ317666, DQ317657, and DQ317652), Spirocercidae (MH038181), Habronematidae (MH038181), and Gongylonematidae (LC026032, LC278392, and LC026029) members ranged from 0.51 (Std Err: 0.06) to 0.54 (Std Err: 0.06). No ITS2 sequences of Physalopteroidea superfamily were available.

The Bayesian trees inferred from cox 1 , nucleotide, and protein sequences, and from $18 \mathrm{~S}$ rRNA genes are shown in Figure 4A,B and Figure 5, respectively. All phylograms provide evidence that $A$. caucasica is an integral part of the genus Physaloptera. In particular, on the cox 1 tree, A. caucasica clustered with Physaloptera sp. (MH752202) and P. retusa (KT894803) isolated respectively from Anolis sagrei in the USA and Tupinambis teguixin in Brazil (Figure 4A). Similarly, on the COI tree, A. caucasica clustered with P. rara (QDF64304), P. retusa (AMX28288), Physaloptera spp. (QEQ27063, AYA23053), P. turgida (AMX28293), and Turgida sp. (AFZ99495) (Figure 4B), while on the 18S rRNA tree, A. caucasica clustered together with Physaloptera apivori (EU004817) and Physaloptera alata (AY702703) isolated from birds in Germany (Figure 5).

In addition, all Physaloptera and A. caucasica haplotypes shared a Euler circuit in the TempletonCrandall-Sing (TCS) network tree for cox 1 sequences. Abbreviata caucasica was connected by three-step branches to the Euler circuit, while all Physaloptera haplotypes were connected to the circuit by one to three-step branches (Figure 6). Hence, the TCS network analysis replicates the same results observed in the Bayesian inferences. 


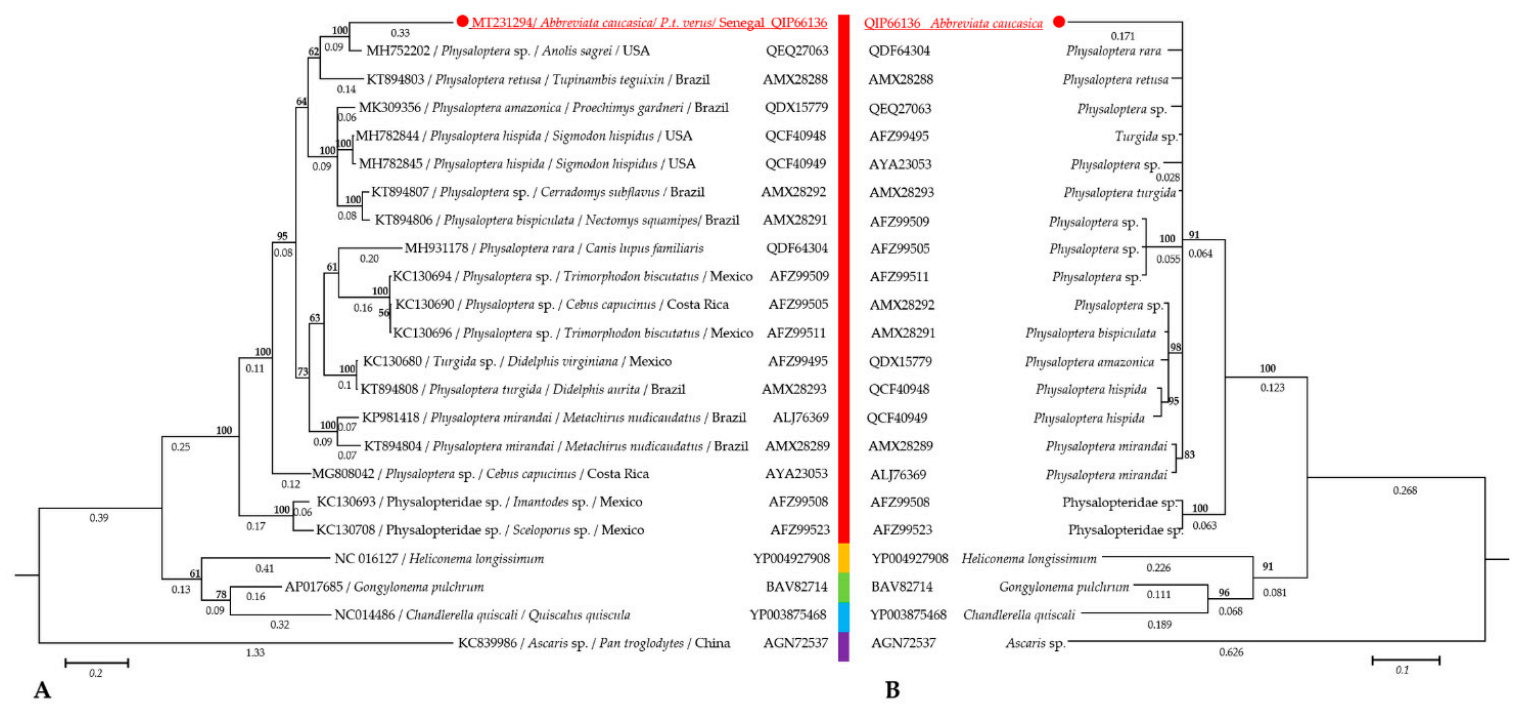

Figure 4. Phylogram generated from Bayesian inference. (A) Based on $651 \mathrm{bp}$ from nucleotide sequences of the cox 1 gene. (B) Based on 210 amino-acid from the COI-protein sequences. Numbers above and below branches are the display of nod statistics and branch length, respectively. Host, geographical location (when available), and GenBank accession numbers and protein-id are indicated. The identity of each taxa is color-coded according to the genus. Likelihood was -5448.2 and -1802.86 for nucleotide and protein inferences, respectively.

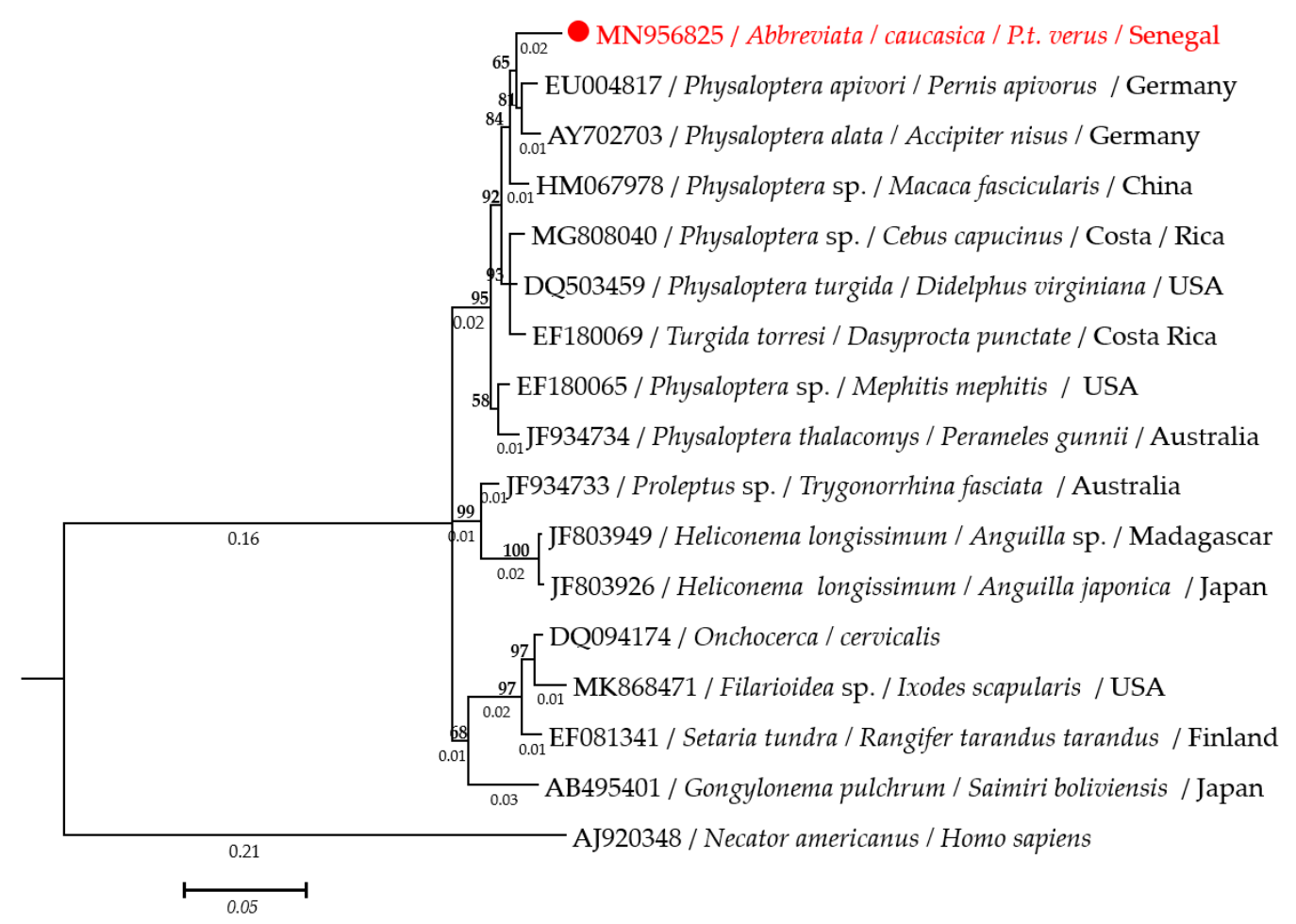

Figure 5. Phylogram generated from Bayesian inference, based on 1209 bp from $18 \mathrm{~S}$ rRNA sequences. Numbers above and below branches are the display of nod statistics and branches length, respectively. Host, geographical location (when available), and GenBank accession numbers are indicated. Likelihood was -3466.3 . 


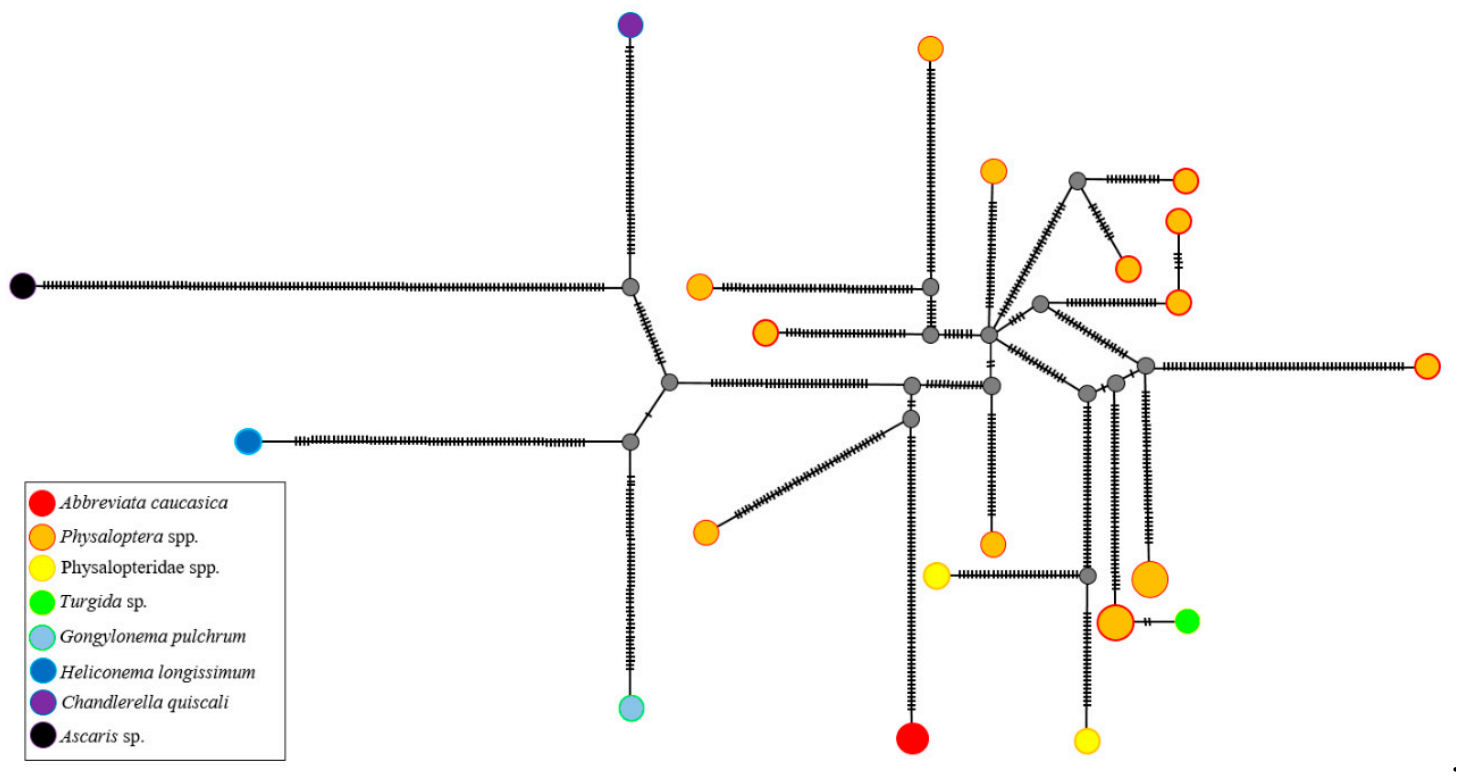

Figure 6. Templeton-Crandall-Sing (TCS) spanning network of the cox1 gene (651 bp) fragment. Colored and greyish circles correspond to a species genotype or hypothetical genotype, respectively. Model characteristics were: nucleotide diversity (pi =1.282), number of segregating sites (361), number of parsimony-informative sites (242), Tajima's D statistic ( $\mathrm{D}=30.3099)$, and $p$ (" $\mathrm{D}>=30.3099$ " $=0$ ).

\subsection{Molecular Investigation of A. caucasica and Nematode Infestation from Biological Samples}

The molecular tool developed in the present study was specific for the target DNA without any amplification from the negative controls.

Results of the molecular screening for A. caucasica and nematode DNA are detailed in Table 2. Among the 48 fecal samples tested, $52.08 \%(n=25)$ were positive for $A$. caucasica, while all environmental samples tested negative. In addition to the samples that tested positive for $A$. caucasica, the pan-Nematoda qPCR assay allowed for the detection of $29.17 \%(n=14)$ of other fecal samples and $6.2 \%(n=7$, three soil samples from termite mounds and four termite specimens) of positive environmental samples.

Table 2. Abbreviata caucasica and nematode infestations regarding origin and fecal consistency.

\begin{tabular}{|c|c|c|c|}
\hline & \multirow{2}{*}{ Tested Samples } & \multicolumn{2}{|c|}{ Infestation Rate (\%) by qPCRs } \\
\hline & & A. caucasica & Nematodes \\
\hline \multicolumn{4}{|l|}{ Localities } \\
\hline Locality 1 & 3 & 0 & 33.3 \\
\hline Locality 2 & 6 & 66.7 & 100 \\
\hline Locality 3 & 39 & 53.8 & 82.1 \\
\hline Total & 48 & 56.3 & 81.3 \\
\hline $\begin{array}{l}\text { Comparison by localities } \\
\text { Fecal consistency }\end{array}$ & Fisher test $(\mathrm{p})$ & 0.148 & 0.052 \\
\hline Fresh & 38 & 40.0 & 70.0 \\
\hline Degraded & 10 & 55.3 & 84.2 \\
\hline Fisher test $(p)$ & $/ /$ & 0.49 & 0.30 \\
\hline
\end{tabular}

Fisher's exact test showed that there were no significant effects of localities and fecal consistency on nematodes and A. caucasica prevalences (Table 2).

Abbreviata caucasica cox 1 species-specific primers successfully amplified a partial sequence (504 bp) from $84 \%(21 / 25)$ of samples identified as positive by the qPCR targeting the 12S rRNA gene. There was no significant difference between both assays according to the McNemar test $(p=0.25)$. All sequences 
were identical to each other and showed $100 \%$ similarity to those from adult specimens amplified with pan-Nematoda primers.

All sequences were deposited in the GenBank database under the following accession numbers: MT231296-MT231316.

\subsection{The Analytical Sensitivity of A. caucasica $12 S$ rRNA qPCR and Egg Counting}

The performance characteristics of the 12S rRNA qPCR are shown in Table S2 and Figure S2. The assay was species specific and was able to detect up to $1.13 \times 10^{-3} \mathrm{eggs} / \mathrm{g}$ of positive fecal samples (i.e., corresponding to $1.13 \times 10^{-5} \mathrm{eggs} / 5 \mu \mathrm{L}$ of DNA). The qPCR efficiency was $101.8 \%$ with -3.28 and 28.68 as a Slope and Y-intercept values, respectively, allowing a perfect adjustment $\left(R^{2}=0.99\right)$.

Table 3 compares the A. caucasica eggs quantified by qPCR in terms of fecal consistency (fresh or degraded samples). Egg concentration in degraded feces $(n=4)$ was low $(<1 / \mathrm{g})$, but was higher $($ mean $=1.4 \mathrm{egg} / \mathrm{g})$ in fresh feces $(n=21)$, while no effect of fecal consistency on egg concentration was observed (ANOVA, R2 $=0.032, \operatorname{Pr}>\mathrm{F}=0.403$ ).

Table 3. Abbreviata caucasica egg output from the positive samples.

\begin{tabular}{cccc}
\hline Fecal Consistency & $\begin{array}{c}\text { Number of Positive } \\
\text { Samples }\end{array}$ & $\begin{array}{c}\text { Quantification (Means Eggs/g) from Positive } \\
\text { Samples }\end{array}$ \\
\hline Degraded & 4 & 0.2 & \\
Fresh & $21^{*}$ & $\mathrm{R} 2$ & 1.4 \\
Statistics & One-way ANOVA & $\mathrm{Pr}>\mathrm{F}$ & 0.032 \\
& & & 0.403 \\
\hline
\end{tabular}

*: one sample with an abnormal residual was removed before statistical analysis. Degraded: decomposing fecal samples.

\section{Discussion}

In this study, we report on the presence of A. caucasica (adults and eggs) in the feces of western chimpanzees from Senegal. Our data indicate that this population of chimpanzees is exposed to a high nematode infestation ( $81.3 \%$ ), particularly A. caucasica (52.1\%). This corroborates previous data from chimpanzees in southeastern Senegal, in which the reported nematode species-specific prevalence was between $0.78 \%$ to $31 \%$ where Physaloptera sp. was often the most prevalent species (13.26 to $31 \%)[12,14]$. However, it was not specified whether these Physaloptera sp. were A. caucasica or author Physaloptera species. Perhaps the use of molecular assays, which were not applied in these studies, could offer a better species resolution.

The adult worms were designated as A. caucasica after careful identification based on the morphological and morphometric features, which was strengthened by previous descriptions by Schulz, (1926), Ortlepp, (1926) and Brede and Burger, (1977) [8,9,21]. In addition to the morphological and morphometric features previously listed, we reported the width of the esophagus $(0.268-0.287 \mathrm{~mm})$ and that of the cuticle $(0.70-0.122 \mathrm{~mm})$, which may help in the future identification of $A$. caucasica. Morphologically, Abbreviata species are closely related to each other [22]. In 1945, Morgan described the utility of uterine morphology (number and mode of origin of the uteri in the female worm) in the taxonomic classification. He classified species from the genus Abbreviata $(n=27)$ into more than three classes with two (didelphys), four (tetra-delphys), or more than four (polydelphys) branches. Of those, three were associated with monkeys: A. caucasica (Linstow, 1902), A. poicilomeira (Sandground, 1936), and A. multipapillata (Kreis, 1940) [4]. Based on the uterine morphology, A. poicilomeira and A. multipapillata are listed in class 5-15 G (5-15 uteri with common trunk), and 9-13 H (9-13 uteri without common trunk), respectively. However, A. caucasica can be easily differentiated by the fact that it is in class 4-D (4 uteri with common trunk).

The morphologic-based classification of Physalopteridae members (e.g., Skrjabinoptera, Abbreviata, and Physaloptera) exclude some morphometric measurements from the taxonomic characters such 
as the length of the esophagus, vulva position, and egg dimensions. These features seem to variate in the same species and are used only in exceptional cases such as P. squamatae (Harwood 1932), S. chamaeleontis (Gedoelst 1916), and S. simplicidens (Ortlepp 1922) [23]. As expected, our data confirmed the variability of these parameters within the A. caucasica (Table 1). This reduced the utility of some commonly used indexes ( $\mathrm{a}, \mathrm{b}$, and $\mathrm{c}$ ) in nematode taxonomy [24].

In addition to the important taxonomic characters highlighted by Fain and Vandepitte (1964) (e.g., morphological features of the anterior end posterior ands, the number of uterine branches), the two adult females measured in the present study exhibited morphometric features of body and egg size close to those of P. mordens (Lipper, 1908), a species synonymous with A. caucasica (Linstow, 1902), where the body size of the female is $41-100 \times 1.8-2.8 \mathrm{~mm}$ with a small egg of 45-49 $\times 32-34 \mu \mathrm{m}$ [7]. Eggs were also similar to those reported by Poinar et al., 1972, where the size is 35-40 $\times 25-35 \mu \mathrm{m}$ [5]. However, A. caucasica (Linstow, 1902) has been described as having a small body size of $24.75-23.84 \times 1.12-1.18 \mathrm{~mm}$ and larger eggs of $57-62 \times 42-45 \mu \mathrm{m}$. In contrast, the measurements from the study of Fain and Vandepitte (1964) showed that the A. caucasica (syn. P. mordens) adult females had a big body size of 108-117 mm and larger eggs of 60-65 $\times 45-55 \mu \mathrm{m}$ (Table 1). Furthermore, the same authors confirmed and described the inconsistency of some measurements within this species [7]. Traditional taxonomic keys are known to be inconclusive for the taxonomic classification of nematodes [25] and should be confirmed by molecular barcoding, which circumvents the limitations of classical morphology-based classification [26]. The question then arises of whether A. caucasica (Linstow, 1902) is the same specie as P. mordens (Lipper, 1908), as indicated by Ortlepp (1926) and Fain and Vandepitte (1964) using morphologic-based taxonomy [7,9]. To address this question, a molecular comparative characterization of the specimens from the studies of Schulz (1926) and Fain and Vandepitte $(1964)[7,8]$ should be performed to confirm or refute the synonymy of these two species.

In our study, we expanded the genetic data available for $A$. caucasica with sequences of mitochondrial and nuclear DNA (i.e., cox1, 12S rRNA, 16S rRNA, 18S rRNA, and ITS2 genes), though the genetic characterization was based on $\operatorname{cox} 1$ and $18 \mathrm{~S}$ rRNA genes, due to the limited data on other gene sequences of Physalopterida members in the GenBank database.

The molecular analyses carried out in this study such as the phylogenetic comparisons of cox 1 and 18S rRNA genes, the TCS network analysis of the cox 1 gene, and the Bayesian inference of both cox 1 and COI sequences confirmed that $A$. caucasica is monophyletic with Physaloptera species (Figures 4A,B and 5). cox 1 and $18 \mathrm{~S}$ rRNA genes are widely used as markers for the molecular barcoding of nematodes [27] with cox 1 sequences of relevance in resolving taxonomic relationships among nematode species $[27,28]$. This gene is described by an interspecific nucleotide pairwise distance (INPD) of $16 \%$ to $27.8 \%$ between nematodes species [29].

The description of new species from the genus Physaloptera as well as the recording of new hosts has quickly evolved over the last decade [30-37]. However, there is a lack of additional data on the epidemiology, life cycle, clinical signs, and description of larval stages in intermediate hosts, which impedes progress in the understanding of these parasites. This is also related to the limited diagnostic and monitoring methods, which has for long time been exclusively based on the identification of eggs in feces [1].

Abbreviata caucasica appears to be capable of living attached to the wall of the digestive tract between the esophagus and the small intestine in human and non-human primates [1,33]. However, clinical features of $A$. caucasica infestation in chimpanzees remain unknown at this time and further studies are needed to identify such features [6].

We developed a specific $12 \mathrm{~S}$ qPCR-based assay for the detection of $A$. caucasica from biological samples and potential intermediate hosts, though the unique Abbreviata species DNA and target sequence from $A$. caucasica used to confirm the assay specificity may represent a limitation of the assay. In contrast, the newly cox 1 A. caucasica specific PCR could be used to assess the identification of A. caucasica from hosts exposed to a wide range of nematode infestations. Since the PCR replicated the same result as the qPCR $(p=0.25)$, both tools were highly sensitive and specific in detecting A. caucasica, 
even the presence of coinfestations, avoiding the hard diagnosis based on egg identification. These tools can resolve problems related to the detection of larval stages from the intermediate and paratenic hosts and therefore avoid the sequencing identification by nematode generic primers. A detection limit as low as $1.13 \times 10^{-3}$ eggs per gram of positive feces, regardless of consistency, solves the problems associated with conventional protocols requiring fresh equipment [38]. Data generated by qPCR showed a rate ranging from 0.2 to 1.4 eggs/g according to the fecal consistency, the best record being $113 \mathrm{egg} / \mathrm{g}$. Appleton and Henzi (1993), reported the same results from baboons in Natal, South Africa, where egg output of $A$. caucasica ranged from 0.32 to $1.48 \mathrm{eggs} / \mathrm{g}$ with $215 \mathrm{eggs} / \mathrm{g}$ as the best record [39]. These observations highlight the usefulness of the qPCR quantification protocol we developed to evaluate the load of A. caucasica eggs. We therefore developed a $5 S$ pan-Nematoda qPCR for the global exploration of nematode infestations from different biological samples.

The absence of $A$. caucasica DNA from all environmental samples could be explained by the fact that they were not contaminated by the feces of infested hosts. However, despite the absence of A. caucasica DNA in the termite (Isoptera spp.) specimens that we tested, we cannot be sure if they are involved in the life cycle of A. caucasica or not. Termites (Isoptera) are the intermediate host of several nematodes such as A. antarctica, achanthocephalans (Thorny-headed worms), and Heterakis gallinarum [40-42].

Poinar and Quentin, (1972) experimentally demonstrated the ability of Blatella germanica and Schistocerca gregaria to develop the infective stage of A. caucasica. However, the life cycle of this nematode remains largely unknown. More than 28 paratenic and second intermediate hosts are also suspected [6]. However, we cannot be sure whether the environmental samples from species included in the diet of the chimpanzee population in our study, screened here, are not implemented in the life cycle of A. caucasica even in the absence of its DNA from all specimens. Termites are known to be the most prevalent arthropod in the chimpanzee diet [43].

\section{Materials and Methods}

\subsection{Study Site and Study Subjects}

Samples were collected at the Dindefelo Community Natural Reserve, located in the Kedougou region, southeastern Senegal, about $35 \mathrm{~km}$ from the town of Kedougou. The vegetation of the reserve is a sudano-guinean savanna woodland [44], one of the driest and more open habitats occupied by the species [45]. All chimpanzees live in multi-female/multi-male communities composed of flexible groups that fission and fuse [46]. At the time of data collection, some individuals were semi-habituated to observers, but the rest remained unhabituated and thus the exact community composition and size were unknown. Although the total home range of Dindefelo chimpanzees was not known, conspecifics living in savanna woodland habitats have extremely large home ranges (e.g., $>85 \mathrm{~km}^{2}$, [47]). Based on size, the fecal samples analyzed in this study were assumed to belong to adults.

\subsection{Fecal, Worms, and Environmental Samples}

Two expeditions to the Dindefelo Community Natural Reserve in Senegal were undertaken in order to collect the samples. During the first trip (August 2016), 49 fecal samples of the western chimpanzee (Pan troglodytes verus) (Figure 7A) were collected from three localities in the reserve: Locality 1, three decomposing "degraded" fecal samples (12.382539, -12.287977); Locality 2, six degraded fecal samples (12.381437, -12.290776); and Locality 3, thirty-eight fresh fecal samples $(12.379919,-12.296830)$. The fecal samples were collected and stored at $-80{ }^{\circ} \mathrm{C}$. Two adult worms were recovered from two fresh feces in the field and stored in 70\% ethanol. In shape and general appearance, these worms resembling Ascaris to the naked eye (Figure 7B). All samples were transported to our laboratory at the Institut Hospitalo-Universitaire (IHU) Méditerranée Infection for further examination, and the adult worms were sent to the parasitology laboratory of the Department of Veterinary Medicine (University of Bari, Italy), where they were subjected to morphological identification. During the 
second expedition (August 2019), we targeted the potential contamination of these parasitic nematodes for the chimpanzees (e.g., the possible intermediate hosts that chimpanzees could eat or their water sources). A total of 113 environmental samples including the main species from the chimpanzee's diet were collected in the vicinity of chimpanzee sleeping sites and other areas frequented by the apes. These included 47 termites, 42 soil samples from termite mounds, 21 plant species, one sample from a water source used by the chimpanzees, a centipede, and one maggot. All samples were preserved in $70 \%$ ethanol and were transported to our laboratory for analysis.

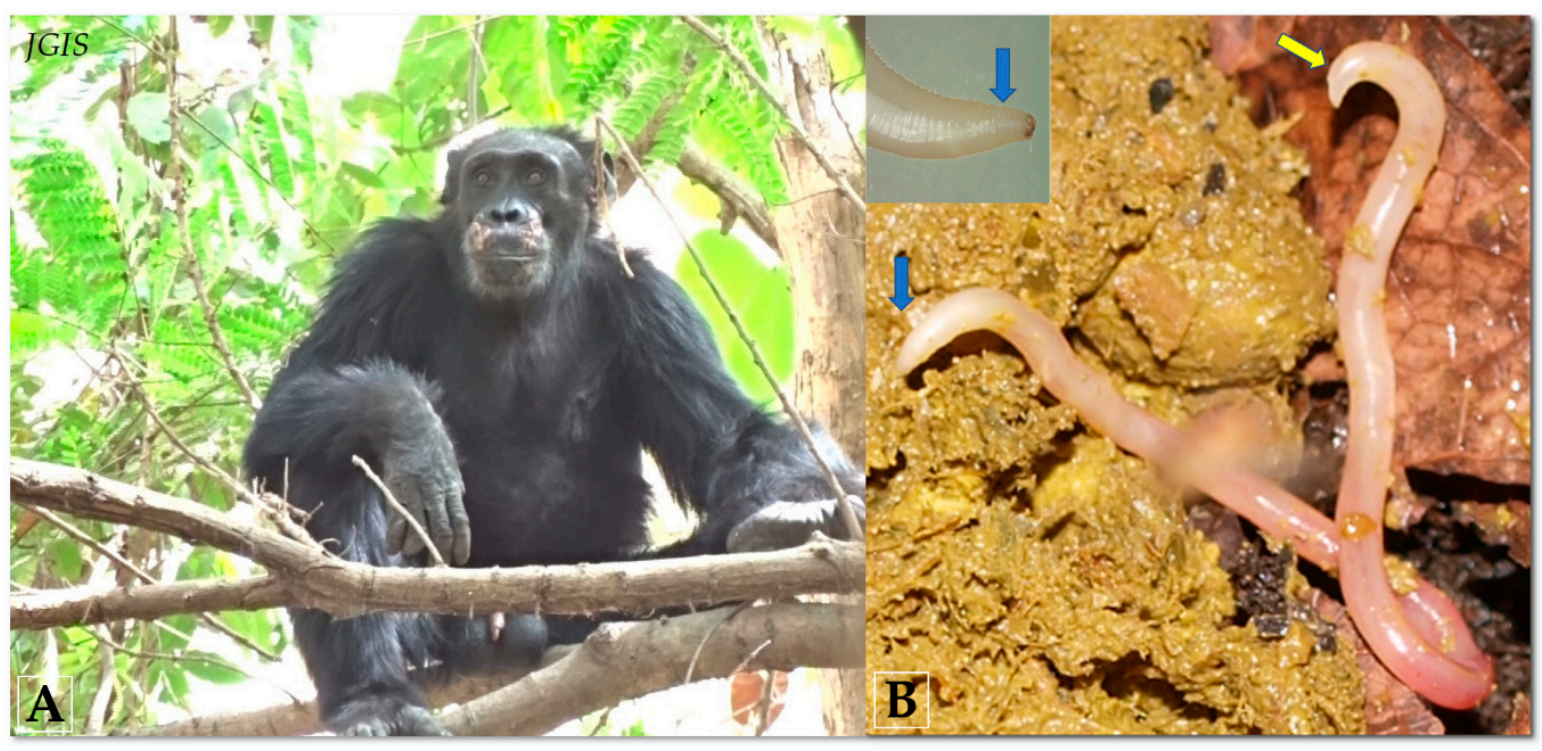

Figure 7. Adult of A. caucasica nematode found in the fecal matter of wild chimpanzee from the Dindefelo Community Natural Reserve, Senegal. (A) A chimpanzee (Pan troglodytes verus) in its natural habitat. (B) Adult female of A. caucasica looks like Ascaris with smooth and elastic body, strangled head, circular mouth (blue arrow), and incurved tail (yellow arrow).

\subsection{Morphological Analysis of A. caucasica Adult Worms}

The female worms were processed for morphometric analysis. The body of the nematodes were measured and then cut into three pieces. The central part was subjected to DNA extraction for molecular identification. The cephalic and caudal ends of the worms were fixed and stained in lactophenol solution to observe anatomical structures. Digital images and measurements were made with an optic microscope Leica ${ }^{\circledR}$ DM LB2 with differential interference contrast. The software Leica ${ }^{\circledR}$ LASAF 4.1 was used for the image analysis process including the measuring of nematodes, which are provided in micrometers. The identification was carried out following the description made by Schulz, (1926), Ortlepp, (1926) and Brede and Burger (1977) $[8,9,21]$.

The observation of structures in the cephalic region, the stout size of the nematode, a thick cuticle finely striated, a large cephalic collarette, the total length, and the distance from the anterior end to the vulva all confirmed the identification of this helminth as $A$. caucasica.

\subsection{Identification of A. caucasica Eggs from Positive Feces}

The exploration of A. caucasica eggs was investigated from two fecal samples from which the adult worms were collected. A formol-ether sedimentation method of fecal concentration was used [48]. Egg identification was carried out according to the key of Fain and Vandepitte (1964) [7], while the differential diagnosis was performed as described elsewhere [49]. 


\subsection{DNA Extraction}

Genomic DNA was extracted from $200 \mathrm{mg}$ of fecal samples, adult worms of $A$. caucasica, and environmental specimens using the QIAGEN DNA tissue kit (QIAGEN, Hilden, Germany) following the manufacturer's recommendations. The extraction was performed after two lysis steps: (i) mechanical lyses performed on a FastPrep-24 ${ }^{\mathrm{TM}} 5 \mathrm{G}$ homogenizer using high speed stirring for $40 \mathrm{~s}$ in the presence of the powder glass, and (ii) enzymatic digestion using the proteinase $\mathrm{K}$ in the appropriate buffer (QIAGEN, Hilden, Germany) for $12 \mathrm{~h}$ at $56^{\circ} \mathrm{C}$. The extracted DNA was then eluted in a total volume of $100 \mu \mathrm{L}$ and stored at $-20^{\circ} \mathrm{C}$.

\subsection{Molecular Characterization of Adult Worms}

\subsubsection{Development of PCR Primer Sets}

The primer sets used in this study are listed in Table 4. First, sequences of the cytochrome $c$ oxidase I (cox1), 16S rRNA, 12S rRNA, and the internal transcribed spacer 2 (ITS2) genes were used to design primer sets targeting nematodes. For each PCR system, a fasta file was constructed from nematode sequences retrieved from the GenBank database. Sequences were aligned using BioEdit v7.0.5.3 software [50]. The highly conserved areas were submitted in Primer3 software v. 0.4.0 [51]. PCRs standardization was performed as described elsewhere [52]. Primers designed are reported in Table 4.

Table 4. Primer sets used for the molecular characterization of A. caucasica.

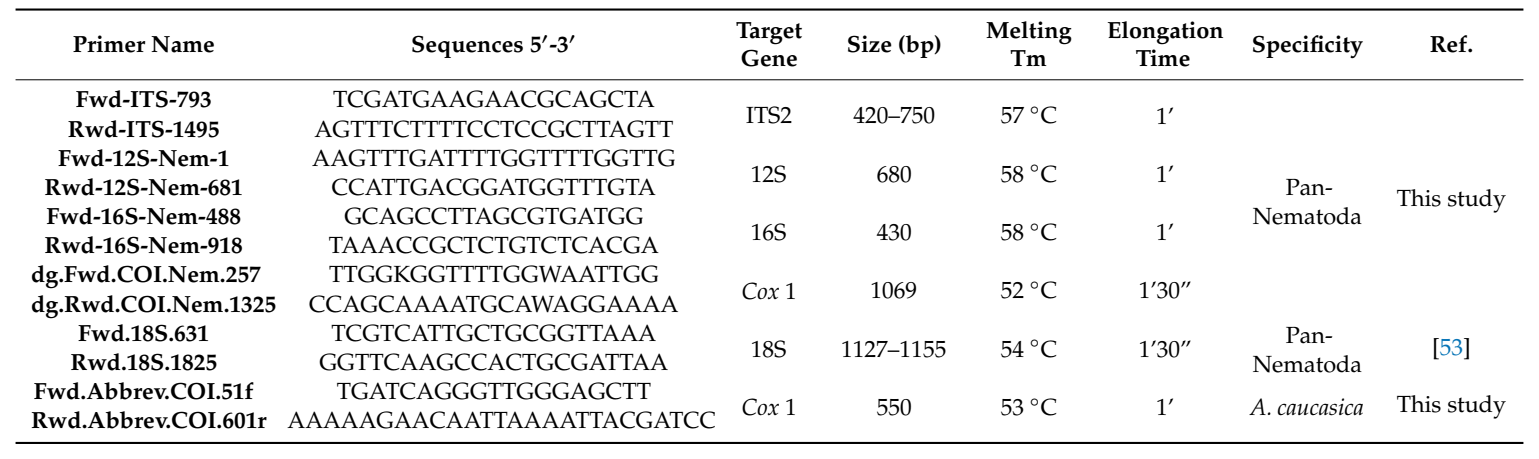

In addition, primers Fwd.18S.631 and Rwd.18S.1825r, recently designed to amplify a partial fragment of the 18S rRNA gene of nematodes, were also used in this study (Table 4) [53]. These genes were chosen in order to compare the relatedness with Physaloptera and parasitic nematodes available in the GenBank database.

\subsubsection{Polymerase Chain Reaction, Sequencing and Phylogenetic Analysis}

All PCR reactions were carried out in a total volume of $50 \mu \mathrm{L}$, consisting of $25 \mu \mathrm{L}$ of AmpliTaq Gold master mix (Thermo Fisher Scientific), $18 \mu \mathrm{L}$ of ultra-purified water DNAse-RNAse free, $1 \mu \mathrm{L}$ of each primer, and $5 \mu \mathrm{L}$ of genomic DNA. PCR reactions with all systems were run using the following protocol: incubation step at $95^{\circ} \mathrm{C}$ for $15 \mathrm{~min}, 40$ cycles of $1 \mathrm{~min}$ at $95{ }^{\circ} \mathrm{C}, 30 \mathrm{~s}$ for the annealing at a different melting temperature for each PCR assay, and elongation for $45 \mathrm{~s}$ to $1 \mathrm{~min}$ and $30 \mathrm{~s}$ (Table 4) at $72{ }^{\circ} \mathrm{C}$ with a final extension for $5 \mathrm{~min}$ at $72{ }^{\circ} \mathrm{C}$. PCR reactions were performed in a Peltier PTC-200 model thermal cycler (MJ Research Inc., Watertown, MA, USA).

The amplicons obtained from each gene examined were purified using the filter plate Millipore NucleoFast 96 PCR kit following the manufacturer's recommendations (Macherey Nagel, Düren, Germany). Purified DNAs were subjected to the second amplification using the BigDye ${ }^{\mathrm{TM}}$ Terminator v3.1 Cycle Sequencing Kit (Applied Biosystems, Foster City, CA, USA). Then, BigDye PCR products 
were purified on the Sephadex G-50 Superfine gel filtration resin prior to sequencing on the ABI Prism 3130XL.

First, all nucleotide sequences were assembled and edited by ChromasPro 2.0.0. The absence of co-amplification of nuclear mitochondrial genes (numts) was verified for the cox 1 DNA sequences, wherein the alignment was performed with the complete sequence of cox 1 DNA from the P. rara mitochondrion sequence (MH931178) using the ClustalW application within Bioedit v.7.2.5. [50]. In addition, the visual verification of sequence chromatograms ambiguities, indels and stop codons of the translated sequences was performed using Chromas Pro 2.0.0 software as recommended [54]. Sequences amplified from the cox1, 16S, 12S, 18S rRNA, and ITS2 genes were subjected separately to a preliminary analysis using the Basic Local Alignment Search Tool (BLAST) [55].

The closely related sequences of Physaloptera and nematode species retrieved from the GenBank database were included in the study and a fasta file was constructed for each gene and then subjected to the alignment. In addition, alignment of nematode COI protein sequences was also performed. All alignments were conducted using the ClustalW application within Bioedit v.7.2.5. [50]. The conservation of amino acids between the COI sequences of $A$. caucasica relative to the sequences of Physaloptera was visualized on CLC Sequence Viewer 7 (CLC Bio Qiagen, Aarhus, Denmark).

From the alignment of each gene examined, the interspecific nucleotide pairwise distance (INPD) was evaluated to estimate the genetic divergence between all species included. Furthermore, the interspecific amino acid pairwise distance (IaaPD) was reproduced for COI-protein sequence alignment. standard errors were obtained by a bootstrap procedure with 1000 replicates using the maximum composite likelihood model [56] and Poisson correction model [57] for nucleotide and protein sequence alignments, respectively. Evolutionary analyses were inferred on MEGA6 software [58].

DNA sequences of Necator americanus (AJ920348) and Ascaris sp. (KC839986) were chosen as out-groups for18S rRNA and cox 1 , respectively, according to the fast-minimum evolution tree on BLAST [55]. The corresponding COI protein sequence of Ascaris sp. (AGN72537) was maintained as an out-group for the COI-protein alignment. The best model parameters with the lowest score were selected to generate phylogenetic trees of aligned $18 \mathrm{~S}$ and $\operatorname{cox} 1$ sequences as well as COI protein sequences by running the MrBayes algorithm on each model using Topaliv2.5 software [59]. The Bayesian phylogenetic tree [60] was inferred for nucleotide sequence alignments using the K80 $(+G)[61]$ and GTR $(+G,+I)[62]$ models, respectively, while the Bayesian phylogenetic tree was inferred on the COI protein sequence alignment using Mtmam (+G) [63]. All phylograms were generated with five runs for 1,100,000 generations, $25 \%$ of burn-in length, and 1000 for sample frequencies.

In order to resolve the haplotype variations of Physaloptera species and A. caucasica, the Fasta file of the $\operatorname{cox} 1$ sequences was converted to the Nexus format using an online converter [64]. During the second time, a Templeton-Crandall-Sing (TCS) network phylogram [65] was inferred with a 95\% connection limit and drawn with 1000 iterations using the PopArt software [66].

\subsection{TaqMan qPCR for Nematoda Parasites Detection}

The 5S rRNA gene was selected for the development of a TaqMan qPCR as an exploratory tool targeting nematode parasites. This choice was based on its conservation among nematodes species [67] and its tandem repetition of 110 times, which improves the assay sensitivity [68]. The partial sequences (XR002251414, JX489168, HM641830, M27961, JX117890, LS997562, U32120, AP018154, LK928622, X16226) representing nematode members from Spirurina and Rhabditida clades were aligned against the 5S gene of some plathelminth worms (Schistosoma mansoni: XR001974633, Spirometra erinaceieuropaei: LN313518, Hymenolepis microstoma: LR215994) and vertebrate hosts (human: AC275639, dog: XR003137316, chimpanzee: XR002941379, horse: XR002802613). Primers: qNem.5S.1f 5'-ACCACGTTGAAAGCACGMC-3'; qNem.5S.110r 5'-TGTCTACAACACCTSGRATTCC-3'; Eurogentec (Liège, Belgium), and a TaqMan probe qNem.5S.38p 6-FAM-5'-AGTTAAGCAACGTTGGGCC-3'-TAMRA; Applied Biosystems ${ }^{\mathrm{TM}}$, were chosen from the highly conserved region specific for nematodes. 


\subsection{Quantitative TaqMan Real-Time PCR ( $q P C R)$ for A. caucasica Detection}

Sequences of the $12 \mathrm{~S}$ rRNA gene amplified from the adult worms of $A$. caucasica were aligned with the closely related sequences of nematodes available in the GenBank using Bioedit v.7.2.5. [50]. The specific regions for $12 \mathrm{~S}$ rRNA of $A$. caucasica were submitted in Primer3 software v. 0.4 .0 [51] in order to design the following primers Phy.12S.f.204:5'-GAATTGGATTAGTACCCAAGTAAGTG-3'/Phy.12S.r.305: 5'-TGTTCCAAAAATCTTTCTAAGATCAG-3' (Eurogentec, Liège, Belgium) and TaqMan probe: Phy.12S.242p. 6VIC-GCGGGAGTAAAGTTAAGTTTAAACC-TAMRA) (Applied Biosystems ${ }^{\mathrm{TM}}$ ), allowing the amplification of a fragment of $101 \mathrm{bp}$.

Both qPCRs were tested in silico within the DNA databases of metazoans (taxid: 33208), vertebrates (taxid: 7742), bacteria (taxid: 2), Canidae (taxid: 9608), Felidae (taxid: 9682), and humans (taxid: 9605). This experiment was performed for both combinations of forward-reward and probe-reverse of each qPCR using Primer-BLAST [69]. Subsequently, the specificity was also validated in vitro against the genomic DNA extracted from adult worms of $A$. caucasica and DNA database including several nematodes, arthropods, laboratory-maintained colonies, hemopathogens as well as human, monkey, donkey, horse, cattle, mouse, and dog as described elsewhere [52].

All qPCR reactions included $5 \mu \mathrm{L}$ of DNA template, $10 \mu \mathrm{L}$ of Master Mix Roche (Eurogentec), and $3 \mu \mathrm{L}$ of ultra-purified water DNAse-RNAse free. Concentration of each primer, UDG, and each probe was $0.5 \mu \mathrm{L}$. The TaqMan reaction of both systems was run using the same cycling conditions. This included two hold steps at $50^{\circ} \mathrm{C}$ and $95^{\circ} \mathrm{C}$ for 2 and $15 \mathrm{~min}$, respectively, followed by 40 cycles of two steps each $\left(95^{\circ} \mathrm{C}\right.$ for $30 \mathrm{~s}$ and $60^{\circ} \mathrm{C}$ for $\left.30 \mathrm{~s}\right)$. The qPCR reaction was performed in a CFX96 Real-Time system (Bio-Rad Laboratories, Foster City, CA, USA) after activating the appropriate dye readers for each qPCR system.

A protocol for the quantification of eggs has been established to assess the analytical sensitivity of qPCR in the detection of fecal infestation. A 10-fold serial dilution of DNA extracted from $200 \mathrm{mg}$ of fecal matter containing 113 eggs (Figure 2) per gram (i.e., 22.6 eggs/100 $\mu \mathrm{L}$ of eluted DNA and 1.13 eggs $/ 5 \mu \mathrm{L}$ of qPCR reaction). Standard curves and derived parameters (PCR efficiency, Slope, Y-intercept, and correlation coefficient) were generated using CFX Manager Software Version 3 [70].

The molecular approaches described above were used to screen the presence of $A$. caucasica and other nematodes in chimpanzee fecal and environmental samples collected in a chimpanzee dormitory.

\subsection{Conventional PCR Specific for A. caucasica}

The use of universal pan-Nematoda primers does not allow for the identification of species-specific DNA sequences due to a non-specific amplification in co-infestations. A specific cox1-based PCR was developed in order to complete the identification of $A$. caucasica from fecal samples. The specific region for A. caucasica was analyzed for the design of the primers COI.51f and COI.601r, targeting $550 \mathrm{bp}$ of the $\operatorname{cox} 1$ gene (Table 1). A. caucasica cox 1 partial sequences herein amplified by the pan-Nematoda primers from the adult worms were aligned with Heliconema longissimum (AN: GQ332423) and Gongylonema pulchrum (AN: AP017685), representative members of Physalopteroidea and Gongylonematidae, respectively.

\subsection{Molecular Survey of A. caucasica and Nematode Infestations in a Chimpanzee Population and the Environmental Samples}

DNA from fecal samples of chimpanzee $(n=48)$ and environmental samples $(n=113)$ were screened for the DNA of A. caucasica and nematode using the $12 \mathrm{~S}$ rRNA A. caucasica and the 5S rRNA pan-Nematoda qPCR assays, respectively. Positive samples for $A$. caucasica were also subjected to amplification and sequencing using the $\operatorname{cox} 1$ A. caucasica-specific primers. 


\subsection{Statistical Analysis}

XLSTAT Addinsoft version 4.1 (XLSTAT 2019: Data Analysis and Statistical Solution for Microsoft Excel, Paris, France) was used for the statistical analysis. Results of qPCRs analysis were used to set a database using the Microsoft Excel ${ }^{\circledR}$ program (Microsoft Corp., Redmond, Washington, USA). The effect of localities and fecal consistency on the infestation rates were tested using the Khi2 test or exact Fisher test. One-way analysis of variance (ANOVA) was performed to compare the predicted eggs from fresh and degraded feces. Negative samples and those with a studentized residual higher than 2.9 were removed before discarding the ANOVA test. McNemar's test was used to compare the detection accuracy of the qPCR and conventional PCR of $A$. caucasica from the chimpanzee samples. Significance level was considered at alpha $\leq 0.05$ for all analyses.

\section{Conclusions}

A. caucasica measurements indicated the inconsistencies of certain indexes such as index $a, b$, and c (Table 1) within this nematode, while it remains distinguishable from other Physaloptera species by the morphological features of the anterior and posterior ends as well as the presence of four uteri with a common trunk. However, the phylogenetic analyses showed that $A$. caucasica are clustered together with other monophyletic species of the Physaloptera genus. In the absence of strong morphological and epidemiological data, the species of Abbreviata may be re-classified as Physaloptera and a revision of the genus is needed. We developed specific and reliable molecular tools for the detection and egg quantification of $A$. caucasica from fecal samples. The tests can ultimately help to identify possible intermediates as well as paratenic hosts involved in the life cycle of $A$. caucasica. We therefore investigated its prevalence in a chimpanzee population from Senegal. Further studies are needed to clarify the epidemiology, circulation, life cycle, and possible pathological effects of A. caucasica, and the role of paratenic hosts or arthropods as intermediate hosts.

Supplementary Materials: The following are available online at http://www.mdpi.com/2076-0817/9/7/517/s1. Figure S1. Abbreviata caucasica partial COI-protein sequences alignment against Physaloptera species. The sequences of A. caucasica (selected box) obtained from adult worms were aligned against Physaloptera sequences available in the GenBank database. Residues were matched as dots. Conserved areas are indicated in blue, while the intensity of mutations is indicated by a foreground color (red to black). Figure S2. Quantification protocol of the $12 S A$. caucasica-specific qPCR. (A) Determination of detection limits and efficiency (eggs/g of fecal matter). (B) Standard curves generated from a serial 10-fold dilution of DNA.

Author Contributions: Conceptualization, O.M. and D.R.; Field study, O.M., D.R., B.D., G.D., and C.S.; Methodology, O.M. and Y.L.; Software, Y.L.; Validation, O.M., D.O., and D.R.; Molecular analysis, Y.L. and H.M.; Parasitological analysis, Y.L., M.S.L., and D.O.; Data curation, O.M. and Y.L.; Writing-original draft preparation, Y.L.; Writing-review and editing, B.D., D.R., D.O., O.M., R.A.H.-A., and A.B. All authors have read and agreed to the published version of the manuscript.

Funding: This study was supported by the Institut Hospitalo-Universitaire (IHU) Méditerranée Infection, the National Research Agency under the program "Investissements d'avenir", reference ANR-10-IAHU-03, the Région Provence-Alpes-Côte d'Azur and European funding FEDER PRIMI.

Acknowledgments: We thank the Direction des Parcs Nationaux and the Direction des Eaux et Forests Chasses et de la Conservation des Sols for permission to work in Senegal. We thank Paula Alvarez Varona, Daouda Diallo, Mamadou F. Diallo, and Mamadou Samba Silla for help in the field in the Dindefelo Community Natural Reserve, Senegal.

Conflicts of Interest: The authors declare no conflict of interest.

\section{References}

1. Strait, K.; Else, J.G.; Eberhard, M.L. Parasitic Diseases of Nonhuman Primates, 2nd ed.; Elsevier Inc: Amsterdam, The Netherlands, 2012; ISBN 9780123813664.

2. Cleeland, L.M.; Reichard, M.V.; Tito, R.Y.; Reinhard, K.J.; Lewis, C.M. Clarifying prehistoric parasitism from a complementary morphological and molecular approach. J. Archaeol. Sci. 2013, 40, 3060-3066. [CrossRef] [PubMed] 
3. Makki, M.; Dupouy-Camet, J.; Seyed Sajjadi, S.M.; Moravec, F.; Naddaf, S.R.; Mobedi, I.; Malekafzali, H.; Rezaeian, M.; Mohebali, M.; Kargar, F.; et al. Human spiruridiasis due to Physaloptera spp. (Nematoda: Physalopteridae) in a grave of the Shahr-e Sukhteh archeological site of the Bronze Age (2800-2500 BC) in Iran. Parasite 2017, 24, 18. [CrossRef] [PubMed]

4. Morgan, B.B. The Nematode genus Abbreviata (Travassos, 1920) Schulz, 1927. Am. Midl. Nat. 1945, 34, 485-490. [CrossRef]

5. Poinar, G.O.; Quentin, J.-C. The development of Abbreviata caucasica (Von Linstow) (Spirurida: Physalopteridae) in an intermediate host. J. Parasitol. 1972, 58, 23-28. [CrossRef] [PubMed]

6. Metzger, S. Gastrointestinal helminthic parasites of habituated wild chimpanzees (Pan troglodytes verus) in the Tai NP, Cote d'Ivoire-including characterization of cultured helminth developmental stages using genetic markers. Ph.D. Thesis, Freie University, Berlin, Germany, 2014.

7. Fain, A.; Vandepitte, J. Description des physaloptères (Abbreviata caucasica Linstow, 1902) récoltés chez l'homme au Congo. Bull. Acad. R. Med. Belg. 1964, 4, 663-682. [PubMed]

8. Schulz, R.-E. Sur la morphologie du Physaloptera caucasica von Linstow, 1902, de l'homme. Ann. Parasitol. Hum. Comparée 1926, 4, 74-84. [CrossRef]

9. Ortlepp, R.J. On the identity of Physaloptera caucasica v. Linstow, 1902, and Physaloptera mordens Leiper, 1908. J. Helminthol. 1926, 4, 199. [CrossRef]

10. Calle, P.P.; Ott Joslin, J. New world and old world monkeys. In Fowler's Zoo and Wild Animal Medicine; Miller, E., Fowler, M., Eds.; Elsevier Inc.: Amsterdam, The Netherlands, 2015; Volume 8, pp. 301-335.

11. Mul, I.F.; Paembonan, W.; Singleton, I.; Wich, S.A.; Van Bolhuis, H.G. Intestinal parasites of free-ranging, semicaptive, and captive Pongo abelii in Sumatra, Indonesia. Int. J. Primatol. 2007, 28, 407-420. [CrossRef]

12. McGrew, W.C.; Tutin, C.E.G.; Collins, D.A.; File, S.K. Intestinal parasites of sympatric Pan troglodytes and Papio spp. at two sites: Gombe (Tanzania) and Mt. Assirik (Senegal). Am. J. Primatol. 1989, 17, 147-155. [CrossRef]

13. Gillespie, T.R.; Lonsdorf, E.V.; Canfield, E.P.; Meyer, D.J.; Nadler, Y.; Raphael, J.; Pusey, A.E.; Pond, J.; Pauley, J.; Mlengeya, T.; et al. Demographic and ecological effects on patterns of parasitism in eastern chimpanzees (Pan troglodytes schweinfurthii) in Gombe National Park, Tanzania. Am. J. Phys. Anthropol. 2010, 143, 534-544. [CrossRef]

14. Howells, M.E.; Pruetz, J.; Gillespie, T.R. Patterns of gastro-intestinal parasites and commensals as an index of population and ecosystem health: The case of sympatric western chimpanzees (Pan troglodytes verus) and guinea baboons (Papio hamadryas papio) at Fongoli, Senegal. Am. J. Primatol. 2011, 73, 173-179. [CrossRef] [PubMed]

15. Kerr, K. Zoonoses: Infectious diseases transmissible from animals to humans. J. Clin. Pathol. 2004, 57, 1120. [CrossRef]

16. Petri, L.H. Life cycle of Physaloptera rara Hall and Wigdor, 1918 (Nematoda: Spiruroidea) with the Cockroach, Blatella germanica, serving as the intermediate host. Trans. Kansas Acad. Sci. 1950, 63, 331-337. [CrossRef]

17. Petri, L.H.; Ameel, D.J. Studies on the life cycle of Physaloptera rara Hall and Wigdor, 1918 and Physaloptera praeputialis Linstow, 1889. J. Parasitol. 1950,36, 6.

18. Olsen, J.L. Life cycle of Physaloptera rara Hall and Wigdor, 1918 (Nematoda: Physalopteroidea) of canids and felids in definitive, intermediate and paratenic hosts. Rev. Iber. Parasitol. 1980, 40, 489-525.

19. Flynn, R.J. Parasites of Laboratory Animals; Iowa State University Press: Ames, IA, USA, 1973; p. 884.

20. Altschul, S.F.; Madden, T.L.; Schäffer, A.A.; Zhang, J.; Zhang, Z.; Miller, W.; Lipman, D.J. Gapped BLAST and PSI-BLAST: A new generation of protein database search programs. Nucleic Acids Res. 1997, 25, 3389-3402. [CrossRef]

21. Brede, H.D.; Burger, P.J. Physaloptera caucasica (=Abbreviata caucasica) in the South African baboon (Papio ursinus). Arb Paul Ehrlich Inst Georg Speyer Haus Ferdinand Blum Inst Frankf A M. 1977, 71, 119-122.

22. Harras, S.F.; Elmahy, R.A. New record of Abbreviata leptosoma Gervais, 1848 (Spirurida: Physalopteridae) infection in two species of lizards in north and south Sinai, Egypt. Egypt. J. Zool. 2019, 72, 1-10.

23. Chabaud, A.G. Essai de révision des Physaloptères parasites de reptiles. Ann. Parasitol. Hum. Comparée 1956. [CrossRef]

24. Fortuner, R. Ratios and indexes in nematode taxonomy. Nematologica 1990, 36, 205-216. [CrossRef]

25. Vovlas, N.; Subbotin, S.A.; Troccoli, A.; Liébanas, G.; Castillo, P. Molecular phylogeny of the genus Rotylenchus (Nematoda, Tylenchida) and description of a new species. Zool. Scr. 2008, 37, 521-537. [CrossRef] 
26. Avó, A.P.; Daniell, T.J.; Neilson, R.; Oliveira, S.; Branco, J.; Adão, H. DNA barcoding and morphological identification of benthic nematodes assemblages of estuarine intertidal sediments: Advances in molecular tools for biodiversity assessment. Front. Mar. Sci. 2017, 4, 66. [CrossRef]

27. Blaxter, M.; Mann, J.; Chapman, T.; Thomas, F.; Whitton, C.; Floyd, R.; Abebe, E. Defining operational taxonomic units using DNA barcode data. Philos. Trans. R. Soc. B Biol. Sci. 2005, 360, 1935-1943. [CrossRef] [PubMed]

28. Meldal, B.H.M.; Debenham, N.J.; De Ley, P.; De Ley, I.T.; Vanfleteren, J.R.; Vierstraete, A.R.; Bert, W.; Borgonie, G.; Moens, T.; Tyler, P.A.; et al. An improved molecular phylogeny of the Nematoda with special emphasis on marine taxa. Mol. Phylogenet. Evol. 2007, 42, 622-636. [CrossRef] [PubMed]

29. Ferri, E.; Barbuto, M.; Bain, O.; Galimberti, A.; Uni, S.; Guerrero, R.; Ferté, H.; Bandi, C.; Martin, C.; Casiraghi, M. Integrated taxonomy: Traditional approach and DNA barcoding for the identification of filarioid worms and related parasites (Nematoda). Front. Zool. 2009, 6, 1. [CrossRef] [PubMed]

30. Pereira, F.B.; Alves, P.V.; Rocha, B.M.; de Souza Lima, S.; Luque, J.L. A new Physaloptera (Nematoda: Physalopteridae) Parasite of Tupinambis merianae (Squamata: Teiidae) from Southeastern Brazil. J. Parasitol. 2012, 98, 1227-1235. [CrossRef]

31. Kalyanasundaram, A.; Henry, C.; Brym, M.Z.; Kendall, R.J. Molecular identification of Physaloptera sp. from wild northern bobwhite (Colinus virginianus) in the Rolling Plains ecoregion of Texas. Parasitol. Res. 2018, 117, 2963-2969. [CrossRef]

32. Sao Luiz, J.; Simoes, R.; Torres, E.; Barbosa, H.; Santos, J.; Giese, E.; Rocha, F.; Maldonado-Junior, A. A new species of Physaloptera (Nematoda: Physalopteridae) from Cerradomys subflavus (Rodentia: Sigmodontidae) in the Cerrado Biome, Brazil. Neotrop. Helminthol. 2015, 9, 301-312.

33. Maldonado, A.; SimAes, R.O.; Luiz, J.S.; Costa-Neto, S.F.; Vilela, R.V. A new species of Physaloptera (Nematoda: Spirurida) from Proechimys gardneri (Rodentia: Echimyidae) from the Amazon rainforest and molecular phylogenetic analyses of the genus. J. Helminthol. 2019, 94, e68. [CrossRef]

34. De Oliveira, M.C.; Lima, V.F.; Pinto, C.L.D.M.; da Silva, É.G.; Teles, D.A.; Ferreira-Silva, C.; Almeida, W.D.O. New record of Physaloptera sp. (Nematoda: Physalopteridae) parasitizing Philodryas nattereri (Ophidia: Dipsadidae) in Brazil. Herpetol. Notes 2019, 12, 1031-1034.

35. Velarde-Aguilar, M.G.; Romero-Mayén, Á.R.; León-Règagnon, V. First report of the genus Physaloptera (Nematoda: Physalopteridae) in Lithobates montezumae (Anura: Ranidae) from Mexico. Rev. Mex. Biodivers. 2014, 85, 304-307. [CrossRef]

36. Ederli, N.B.; Gallo, S.S.M.; Oliveira, L.C.; de Oliveira, F.C.R. Correction to: Description of a new species Physaloptera goytaca n. sp. (Nematoda, Physalopteridae) from Cerradomys goytaca Tavares, Pessôa \& Gonçalves, 2011 (Rodentia, Cricetidae) from Brazil. Parasitol. Res. 2018, 117, 2757-2766. [PubMed]

37. Leiper, B.Y.R.T. Observation on certain helminths of men. Trans. R. Soc. Trop. Med. Hyg. 1915, 6, $265-297$. [CrossRef]

38. Pouillevet, H.; Dibakou, S.-E.; Ngoubangoye, B.; Poirotte, C.; Charpentier, M.J.E. A comparative study of four methods for the detection of nematode eggs and large protozoan cysts in mandrill faecal material. Folia Primatol. 2017, 88, 344-357. [CrossRef] [PubMed]

39. Appleton, C.C.; Henzi, S.P. Environmental correlates of gastrointestinal parasitism in montane and lowland baboons in Natal, South Africa. Int. J. Primatol. 1993, 14, 623-635. [CrossRef]

40. Anderson, R.C. Nematode parasites of vertebrates. In Their Development and Transmission, 2nd ed.; CABI Publishing: Wallingford, Oxon, UK, 2000; p. 650.

41. Martin, J. Australian mammals: Biology and captive management. Austral. Ecol. 2005, 30, 126-129. [CrossRef]

42. King, C.; Jones, H.I.; Tay, C.Y. Arthropod intermediate hosts of Abbreviata antarctica (Nematoda: Physalopteridae) in Australia. J. Parasitol. 2013, 99, 708-711. [CrossRef]

43. McGrew, W.C. Chimpanzee Material Culture: Implications for Human Evolution; Cambridge University Press: Cambridge, UK, 1993; p. 277.

44. Pacheco, L.; Fraixedas, S.; Fernández-Llamazares, Á.; Estela, N.; Mominee, R.; Guallar, F. Perspectives on sustainable resource conservation in community nature reserves: A case study from senegal. Sustainability 2012, 4, 3158-3179. [CrossRef]

45. McGrew, W.C.; Baldwin, P.J.; Tutin, C.E.G. Chimpanzees in a hot, dry and open habitat: Mt. Assirik, Senegal, West Africa. J. Hum. Evol. 1981. [CrossRef] 
46. Nishida, T. The social group of wild chimpanzees in the Mahali Mountains. Primates 1968, 9, 167-224. [CrossRef]

47. Rudicell, R.S.; Piel, A.K.; Stewart, F.; Moore, D.L.; Learn, G.H.; Li, Y.; Takehisa, J.; Pintea, L.; Shaw, G.M.; Moore, J.; et al. High Prevalence of Simian Immunodeficiency Virus Infection in a Community of Savanna Chimpanzees. J. Virol. 2011. [CrossRef] [PubMed]

48. Gillespie, T.R. Noninvasive assessment of gastrointestinal parasite infections in free-ranging primates. Int. J. Primatol. 2006, 27, 1129-1143. [CrossRef]

49. Jessee, M.T.; Schilling, P.W.; Stunkard, J.A. Identification of intestinal helminth eggs in old world primates. Lab. Anim. Care 1970, 20, 83-87. [PubMed]

50. Hall, T.; Biosciences, I.; Carlsbad, C. BioEdit: An important software for molecular biology. GERF Bull. Biosci. 2011, 2, 60-61.

51. Koressaar, T.; Lepamets, M.; Kaplinski, L.; Raime, K.; Andreson, R.; Remm, M. Primer3_masker: integrating masking of template sequence with primer design software. Bioinformatics 2018, 34, 1937-1938. [CrossRef] [PubMed]

52. Laidoudi, Y.; Davoust, B.; Varloud, M.; Niang, E.H.A.; Fenollar, F.; Mediannikov, O. Development of a multiplex qPCR-based approach for the diagnosis of Dirofilaria immitis, D. repens and Acanthocheilonema reconditum. Parasites Vectors 2020, 13, 319. [CrossRef]

53. Laidoudi, Y.; Ringot, D.; Watier-grillot, S.; Davoust, B.; Mediannikov, O. A cardiac and subcutaneous canine dirofilariosis outbreak in a kennel in central France. Parasite 2019, 26, 72. [CrossRef]

54. Song, H.; Buhay, J.E.; Whiting, M.F.; Crandall, K.A. Many species in one: DNA barcoding overestimates the number of species when nuclear mitochondrial pseudogenes are coamplified. Proc. Natl. Acad. Sci. USA 2008, 105, 13486-13491. [CrossRef]

55. Altschul, S.F.; Gish, W.; Miller, W.; Myers, E.W.; Lipman, D.J. Basic local alignment search tool. J. Mol. Biol. 1990, 215, 403-410. [CrossRef]

56. Tamura, K.; Nei, M.; Kumar, S. Prospects for inferring very large phylogenies by using the neighbor-joining method. Proc. Natl. Acad. Sci. USA 2004, 101, 11030-11035. [CrossRef]

57. Zuckerkandl, E.; Pauling, L. Evolutionary divergence and convergence in proteins. Evolv. Genes Proteins 1965. [CrossRef]

58. Tamura, K.; Stecher, G.; Peterson, D.; Filipski, A.; Kumar, S. MEGA6: Molecular evolutionary genetics analysis version 6.0. Mol. Biol. Evol. 2013, 30, 2725-2729. [CrossRef] [PubMed]

59. Milne, I.; Lindner, D.; Bayer, M.; Husmeier, D.; Mcguire, G.; Marshall, D.F.; Wright, F. TOPALi v2: A rich graphical interface for evolutionary analyses of multiple alignments on HPC clusters and multi-core desktops. Bioinformatics 2009, 25, 126-127. [CrossRef]

60. Huelsenbeck, J.P.; Ronquist, F. MRBAYES: Bayesian inference of phylogenetic trees. Bioinformatics 2001, 17, 754-755. [CrossRef] [PubMed]

61. Kimura, M. A simple method for estimating evolutionary rates of base substitutions through comparative studies of nucleotide sequences. J. Mol. Evol. 1980, 16, 111-120. [CrossRef]

62. Waddell, P.J.; Steel, M.A. General time-reversible distances with unequal rates across sites: Mixing Y and inverse Gaussian distributions with invariant sites. Mol. Phylogenet. Evol. 1997, 8, 398-414. [CrossRef]

63. Cao, Y.; Janke, A.; Waddell, P.J.; Westerman, M.; Takenaka, O.; Murata, S.; Okada, N.; Pääbo, S.; Hasegawa, M. Conflict among individual mitochondrial proteins in resolving the phylogeny of eutherian orders. J. Mol. Evol. 1998, 47, 307-322. [CrossRef]

64. Rice, P.; Longden, I.; Bleasby, A. EMBOSS: the European Molecular Biology Open Software Suite. Trends Genet. 2000, 16, 276-277. [CrossRef]

65. Clement, M.; Posada, D.; Crandall, K.A. TCS: A computer program to estimate gene genealogies. Mol. Ecol. 2000, 9, 1657-1659. [CrossRef]

66. Leigh, J.; Bryant, D.; Steel, M. PopART (Population Analysis with Reticulate Trees). 2015. Available online: http://popart.otago.ac.nz/index.shtml (accessed on 22 June 2020).

67. Bamuhiiga, J.; Williams, S.A.; Fischer, P.; Büttner, D.W. Detection of the filarial parasite Mansonella streptocerca in skin biopsies by a nested polymerase chain reaction-based assay. Am. J. Trop. Med. Hyg. 2017, 58, 816-820.

68. Huang, X.Y.; Hirsh, D. A second trans-spliced RNA leader sequence in the nematode Caenorhabditis elegans. Proc. Natl. Acad. Sci. USA 1989, 86, 8640-8644. [CrossRef] [PubMed] 
69. Ye, J.; Coulouris, G.; Zaretskaya, I.; Cutcutache, I.; Rozen, S.; Madden, T.L. Primer-BLAST: A tool to design target-specific primers for polymerase chain reaction. BMC Bioinform. 2012, 13, 134. [CrossRef] [PubMed]

70. Bio-Rad, L. Real-Time PCR Applications Guide; Bio-Rad Laboratories Inc.: Hercules, CA, USA, 2006; p. 41.

(C) 2020 by the authors. Licensee MDPI, Basel, Switzerland. This article is an open access article distributed under the terms and conditions of the Creative Commons Attribution (CC BY) license (http://creativecommons.org/licenses/by/4.0/). 